\title{
Painless Mobile Nodule on the Shoulder
}

Preeya T. Shah, MD; Patrick M. Kupiec, MD; Allen Strickler, MD, PhD; Eric W. Hossler, MD

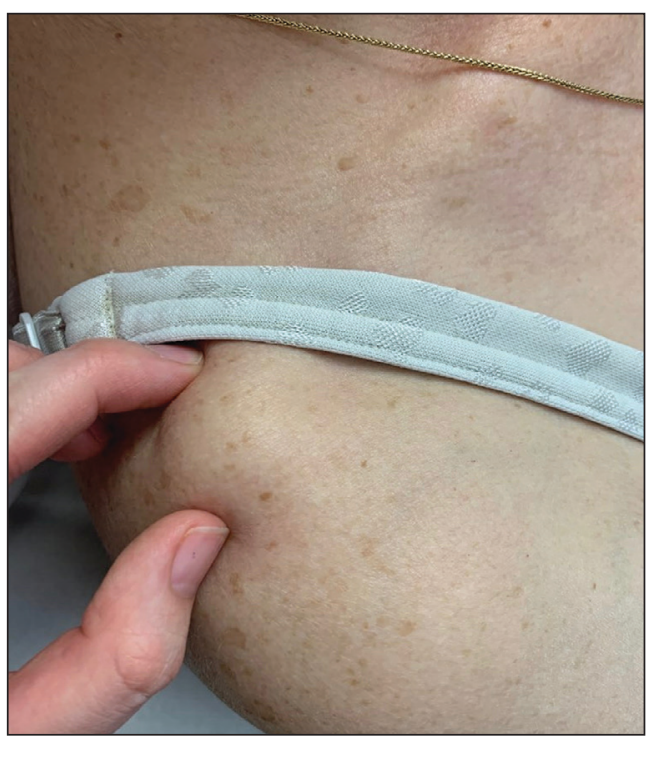

A 70-year-old woman presented to the outpatient dermatology clinic with an acute-onset lesion on the right shoulder. She first noticed a "cyst" developing in the area approximately 3 weeks prior but noted that it may have been present longer. The lesion was bothersome when her undergarments rubbed against it, but she otherwise denied pain, increase in size, or drainage from the site. Her medical history was remarkable for a proliferating trichilemmal tumor on the right parietal scalp treated with Mohs surgery approximately 13 years prior to presentation. She had no personal or family history of skin cancer. Physical examination revealed a $2.5-\mathrm{cm}$, mobile, nontender, flesh-colored subcutaneous nodule on the right shoulder (top); no ulceration, bleeding, or drainage was present. The surrounding skin demonstrated no clinical changes. The patient was scheduled for outpatient surgical excision of the nodule, which initially was suspected to be a lipoma. During the excision, a translucent cystlike nodule (bottom) was gently dissected and sent for histopathologic examination.

\section{WHAT'S YOUR DIAGNOSIS?}
a. cutaneous ciliated cyst
b. cutaneous metaplastic synovial cyst
c. epidermoid cyst
d. ganglion cyst
e. nodular hidradenoma

PLEASE TURN TO PAGE E40 FOR THE DIAGNOSIS

Dr. Shah was from Marshall University Joan C. Edwards School of Medicine, Huntington, West Virginia, and currently is from the Department of Internal Medicine, University of Virginia, Charlottesville. Drs. Kupiec, Strickler, and Hossler are from the Department of Dermatology, Geisinger Medical Center, Danville, Pennsylvania. Drs. Strickler and Hossler also are from the Department of Pathology. The authors report no conflict of interest.

Correspondence: Preeya T. Shah, MD, University of Virginia Medical Center, 1300 Jefferson Park Ave, Charlottesville, VA 22903 (pts9x@virginia.edu). doi:10.12788/cutis.0194 


\section{THE DIAGNOSIS: Cutaneous Metaplastic Synovial Cyst}

G ross examination of the excised nodule revealed a $2.5 \times 1.2 \times 1.0-\mathrm{cm}$, intact, gray-white, thin-walled, smooth-lined nodule filled with clear mucinouslike material. Hematoxylin and eosin-stained sections demonstrated a dermal-based cystlike structure composed of a lining of connective tissue with hyalinized material and fibrin as well as spindle and epithelioid cells with a mild mixed inflammatory infiltrate (Figure). These histopathologic findings led to the diagnosis of cutaneous metaplastic synovial cyst (CMSC).

Cutaneous metaplastic synovial cyst, also known as synovial metaplasia of the skin, is an uncommon benign cystic lesion that was first reported by Gonzalez et $\mathrm{al}^{1}$ in 1987. Histologically, CMSC lacks an epithelial lining and therefore is not a true cyst but rather a pseudocyst. ${ }^{2}$ Clinically, the lesion typically presents as a solitary subcutaneous nodule that may be tender or painless. In a literature review of CMSC cases performed by Fukuyama et $\mathrm{al}^{3}{ }^{3}$ distribution of reported cases according to body site varied; however, limbs were found to be the most commonly involved area. A PubMed search of articles indexed for MEDLINE as well as a Google Scholar search using the term cutaneous metaplastic synovial cyst revealed at least 37 cases reported in the English-language literature, ${ }^{3-9}$ including our present case. The pathogenesis remains uncertain; however, a majority of previously reported cases of CMSC characteristically have been associated with a pre-existing lesion, with most presentations developing at surgical scar sites secondary to operation or trauma. ${ }^{5}$ Relative tissue fragility secondary to rheumatoid arthritis $^{10}$ and Ehlers-Danlos syndrome ${ }^{9,11,12}$ has been linked to CMSC in some documented reports, while a minority of cases report no antecedent events triggering formation of the lesion. ${ }^{13-15}$

As evidenced by our patient, CMSC clinically mimics several other benign entities; histopathologic examination is necessary to confirm the diagnosis. Although nodular hidradenoma also may clinically present as a solitary firm intradermal nodule, microscopy reveals a dermal-based lobulated tumor containing cystic spaces and solid areas composed of basophilic polyhedral cells and round glycogen-filled clear cells. ${ }^{16}$ Epidermoid cysts are differentiated from CMSC by the presence of a cyst wall lining composed of stratified squamous epithelium and associated laminated keratin within the lumen, ${ }^{17}$ which corresponds to its pearly white appearance on gross examination. Cutaneous ciliated cysts predominantly occur on the lower extremities of young women and are lined by simple cuboidal or columnar ciliated cells that resemble müllerian epithelium. ${ }^{18}$ Similar to

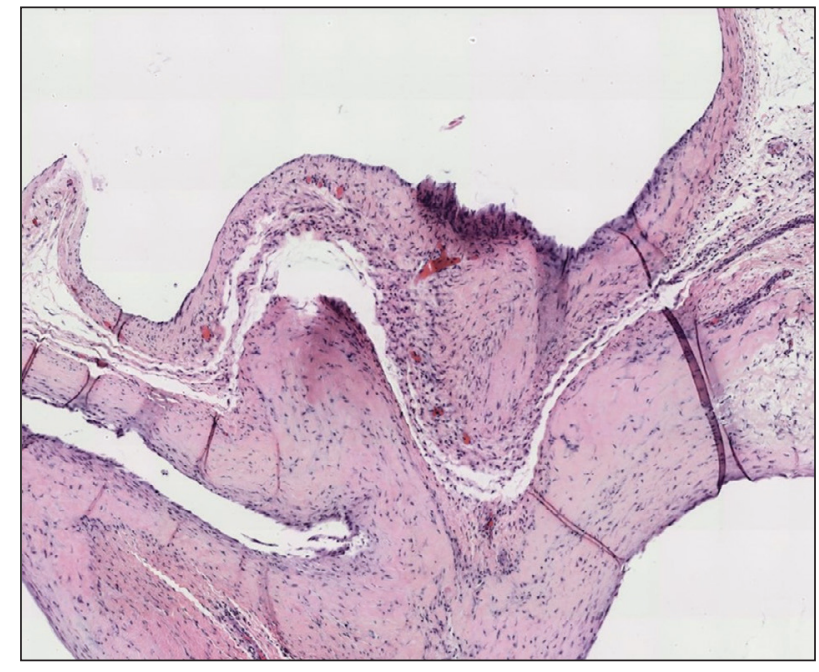

Cutaneous metaplastic synovial cyst. Dermal-based cystlike structure composed of a lining of connective tissue with hyalinized material and fibrin as well as spindle and epithelioid cells with a mild mixed inflammatory infiltrate $(\mathrm{H \& E}$, original magnification $\times 50)$.

CMSC, ganglion cysts are pseudocysts that lack a true epithelial lining but differ in appearance due to their mucin-filled synovial-lined sac. ${ }^{19}$ Additionally, ganglion cysts most often occur on the dorsal and volar aspects of the wrist.

Excisional biopsy is indicated as the preferred treatment of CMSC, given the lesion's benign behavior and low recurrence rate. ${ }^{6}$ Our case highlights this rare entity and reinforces its inclusion in the differential diagnosis of subcutaneous mobile nodules, especially in the setting of prior tissue injury secondary to trauma, surgical procedures, or conditions such as rheumatoid arthritis or Ehlers-Danlos syndrome. Unlike most previously reported cases, our patient reported no preceding tissue injury associated with formation of the lesion, and she was largely asymptomatic on presentation. Considering the limited number of CMSC cases demonstrated in the literature, it is important to continue reporting new cases to better understand characteristics and presentations of this uncommon lesion.

\section{REFERENCES}

1. Gonzalez JG, Ghiselli RW, Santa Cruz DJ. Synovial metaplasia of the skin. Am J Surg Pathol. 1987;11:343-350.

2. Calonje E, Brenn T, Lazar A, et al. Cutaneous cysts. In: Calonje E, Brenn T, Lazar A, et al. McKee's Pathology of the Skin. 5th ed. Elsevier Limited; 2020:1680-1697.

3. Fukuyama M, Sato Y, Hayakawa J, et al. Cutaneous metaplastic synovial cyst: case report and literature review from the dermatological point of view. Keio J Med. 2016;66:9-13. 
4. Karaytug K, Kapicioglu M, Can N, et al. Unprecedented recurrence of carpal tunnel syndrome by metaplastic synovial cyst in the carpal tunnel. Acta Orthop Traumatol Turc. 2019;53:230-232.

5. Martelli SJ, Silveira FM, Carvalho PH, et al. Asymptomatic subcutaneous swelling of lower face. Oral Surg Oral Med Oral Pathol Oral Radiol. 2019;128:101-105.

6. Majdi M, Saffar H, Ghanadan A. Cutaneous metaplastic synovial cyst: a case report. Iran J Pathol. 2016;11:423-426.

7. Ramachandra S, Rao L, Al-Kindi M. Cutaneous metaplastic synovial cyst. Sultan Qaboos Univ Med J. 2016;16:E117-E118.

8. Heidarian A, Xie Q, Banihashemi A. Cutaneous metaplastic synovial cyst presenting as an axillary mass after modified mastectomy and adjuvant radiotherapy. Am J Clin Pathol. 2016;146:S2.

9. Fernandez-Flores A, Barja-Lopez JM. Cutaneous metaplastic synovial cyst in Ehlers-Danlos syndrome. J Cutan Pathol. 2020;47:729-733.

10. Choonhakarn C, Tang S. Cutaneous metaplastic synovial cyst. J Dermatol. 2003;30:480-484.

11. Guala A, Viglio S, Ottinetti A, et al. Cutaneous metaplastic synovial cyst in Ehlers-Danlos syndrome: report of a second case. Am J Dermatopathol. 2008;30:59-61.
12. Nieto S, Buezo GF, Jones-Caballero M, et al. Cutaneous metaplastic synovial cyst in an Ehlers-Danlos patient. Am J Dermatopathol. 1997;19:407-410.

13. Goiriz R, Rios-Buceta L, Alonso-Perez A, et al. Cutaneous metaplastic synovial cyst. J Am Acad Dermatol. 2005;53:180-181.

14. Kim BC, Choi WJ, Park EJ, et al. Cutaneous metaplastic synovial cyst of the first metatarsal head area. Ann Dermatol. 2011;23 (suppl 2):S165-S168.

15. Yang HC, Tsai YJ, Hu SL, et al. Cutaneous metaplastic synovial cyst-a case report and review of literature. Dermatol Sinica. 2003;21:275-279.

16. Kataria SP, Singh G, Batra A, et al. Nodular hidradenoma: a series of five cases in male subjects and review of literature. Adv Cytol Pathol. 2018;3:46-47.

17. Mohamed Haflah N, Mohd Kassim A, Hassan Shukur M. Giant epidermoid cyst of the thigh. Malays Orthop J. 2011;5:17-19.

18. Torisu-Itakura H, Itakura E, Horiuchi $\mathrm{R}$, et al. Cutaneous ciliated cyst on the leg of a woman of menopausal age. Acta Derm Venereol. 2009;89:323-324.

19. Fullen DR. Cysts and sinuses. In: Busam K, ed. Dermatopathology. Saunders; 2010:300-330. 